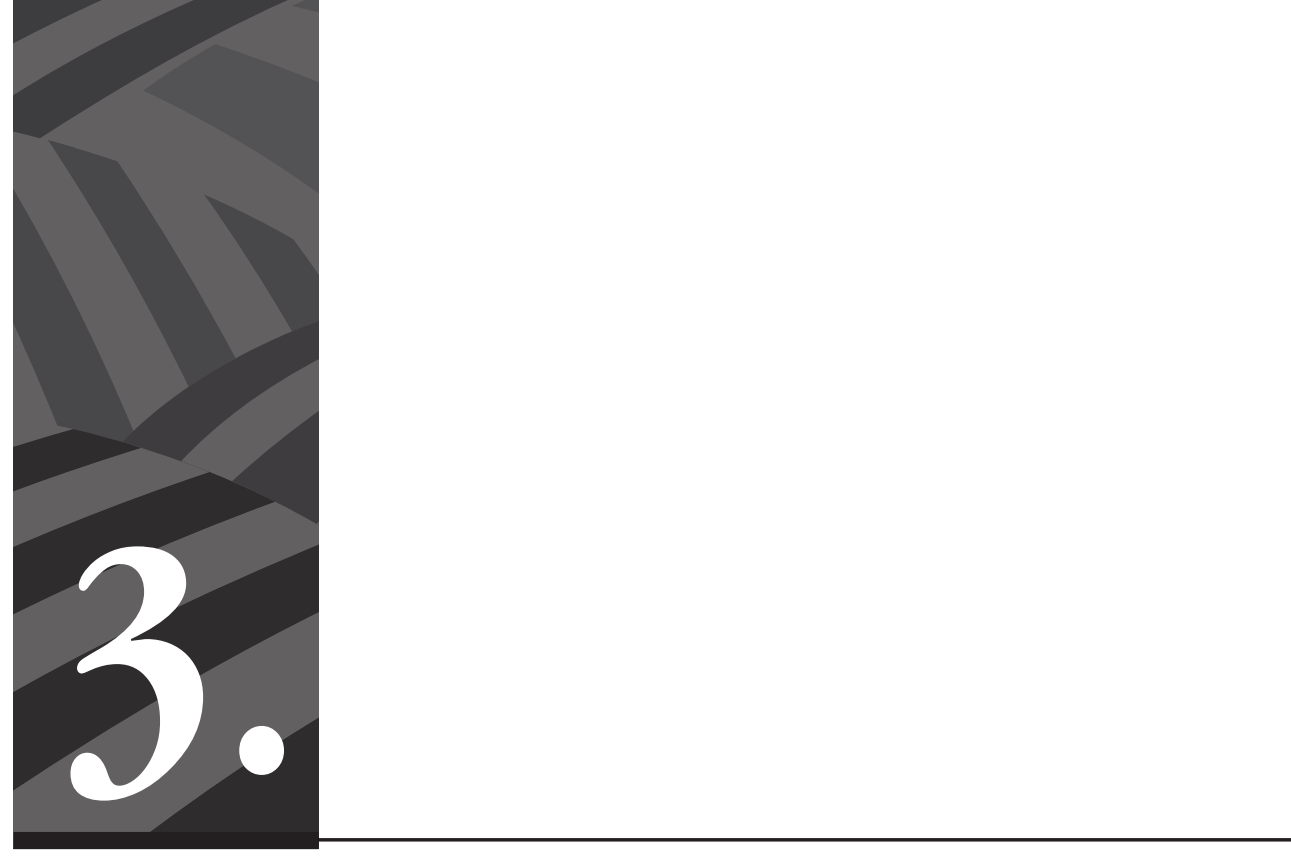

Sobre la velocidad de la muerte, sus formas de captura y la extracción de carbón en Cerrejón 


\section{Sobre la velocidad de la muerte, sus formas de captura y la extracción de carbón en Cerrejón}

\section{Por Oscar Pedraza*}

Resumen: en este artículo se discuten las dificultades, tensiones y conflictos que emergen en la construcción de casos de violaciones a derechos humanos relacionadas con minería. El artículo se concentra principalmente en los retos que enfrentan abogados y activistas de derechos humanos Colombia. Entre esos retos se encuentran: 1) La relación entre derechos humanos y minería, que implican paradigmas jurídicos, políticos y epistémicos cualitativamente distintos y obligan a la reelaboración en las formas de trabajo de quienes participan en los casos; 2) las disputas concretas en torno al estatus de verdad de los datos que sustentan las pruebas y los argumentos jurídicos, políticos y morales; 3 ) las diferentes formas de la muerte, que deben ser capturadas a través de prácticas, epistemologías e instituciones que no siempre son las adecuadas.

Palabras clave: movimientos sociales, carbón, extractivismo, expertos, onG, saberes, derechos humanos, antropología jurídica.

\section{On speed of death, its forms of capture and the coal extraction in Cerrejón}

Abstract: This paper discusses the tensions and conflicts that emerge in the processes of making cases of human rights violations linked to mining extraction. I focus on the challenges that human rights lawyers and activists, who have become experts in the art of assembling cases of human rights related

* Historiador y Antropólogo Universidad de los Andes. Master en Antropología New School for Social Research. Candidato a Ph.D. en antropología University of New York, Graduate Center. 
to political violence in a context of war face when confronted to the making of human rights cases related to mining. Among these challenges are: 1) the relation between human rights and mining, which involve legal, political and epistemic paradigms that are often different, forcing the actors involved to reelaborate them; 2) the disputes on the truth status of the date used to sustain judicial, moral and political arguments and proofs; 3) different modalities of death that need to be captured, often with epistemological and political tools that are not always adequate.

Keywords: social movements, coal, extractivism, experts, NGO's

Cómo citar este artículo: Pedraza, Oscar (2017). Sobre la velocidad de la muerte, sus formas de captura y la extracción de carbón en Cerrejón. Revista Controversia, 208, 103-132.

Fecha de recepción: 25 de enero del 2017

Fecha de aprobación: 5 de abril del 2017

"Beware of the horses

A horse is a horse

Of course,

But who rides is important"

Run The Jewels. A Report to the Shareholders/Kill Your Masters

Run the Jewels ${ }^{1}$

\section{Introducción}

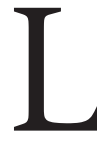

a popular frase "para morirse solo hace falta estar vivo", más allá de ser una obviedad, alude a una condición de precariedad inherente a la vida, afirmando que de una u otra manera estamos siempre al borde de la muerte, siempre en el límite de una vida que se apaga. Esa fragilidad pareciera situarnos en aparente igualdad como seres humanos, es decir, pareciera decir que todas las vidas valen lo

1 Run the Jewels, RTJ, es una banda estadounidense de rap. 
mismo porque, de alguna manera, todas las vidas están siempre al filo de la muerte.

Pero no hay que excavar demasiado en esa frase para darse cuenta que esconde algo. La idea de que todas las vidas valen lo mismo y que todas las muertes son condenables se estrella con las condiciones materiales, políticas, históricas y afectivas, que jerarquizan tanto el valor de la vida como el valor de la muerte. Aunque parece obvio que aspectos como el lugar donde alguien muere, su posición social, raza o género, estatus político y otra serie de elementos definen la importancia relativa de la muerte; lo cierto es que muy poco se ha discutido en torno a la forma en que las muertes adquieren valor, algo que es mucho más difícil de plantear en contextos como el colombiano, donde la impunidad y el olvido son parte del combate que libran cientos de activistas y familiares de víctimas todos los días.

Tal vez por lo abrumador de la impunidad y el silencio que encubre las miles de violaciones a la vida de las personas en medio de la guerra, es tan importante preguntarse qué hace que ciertas muertes adquieran más importancia que otras y qué lleva a otras muertes a caer en el olvido. Para esto, se parte de las siguientes afirmaciones: 1) ser víctima de una violación a los derechos humanos no significa convertirse en un caso de derechos humanos; 2) el universalismo, que presume la capacidad de valorar de manera equitativa la vida como principio fundante de los derechos humanos, se enfrenta con las prácticas, materialidades, instituciones y discursos que jerarquizan el valor de la vida y la muerte; y 3) hay formas de morir y velocidades de la muerte que escapan a los dispositivos diseñados por las instituciones, las prácticas y los discursos de los derechos humanos, haciéndolas ilegibles o intraducibles, condenándolas a veces al silencio, a la imposibilidad de existir en los regímenes del posconflicto, la transición y la reconciliación.

Por lo tanto, un evento violento no se convierte de manera automática en un caso de derechos humanos o en un artefacto moral y político 
que circula en las redes de los derechos humanos. No hay nada inherentemente natural a la muerte que la defina como importante y, por ello, es necesario analizar las prácticas, discursos y dispositivos que hacen posible que una muerte se vuelva relevante. Ahora bien, esto se complica cuando se introduce la relación de lo humano, la muerte y la naturaleza en la forma contemporánea de su apropiación y explotación en América Latina, específicamente el problema del neoextractivismo. En el caso colombiano, aunque la relación entre violaciones a derechos humanos y las condiciones que las producen se enuncian en foros, reuniones, artículos, reportes de ONG y agencias estatales, existe una serie de elementos que parece fracturar la relación entre las violaciones a derechos humanos, relacionadas con el extractivismo, con aquellas en las que es posible discernir con claridad su dimensión eminentemente política $^{2}$. En el contexto de las negociaciones con las FARC-EP, donde el lugar de la naturaleza privilegió al uso de la tierra y donde "el modelo de desarrollo no está en discusión”, la violencia relacionada explícitamente con el extractivismo - para el caso de este escrito, la minería a gran escala de empresas multinacionales - ha tenido difícil cabida y se muestra como un interrogante para el futuro sin guerra.

En este escrito se discutirán algunas de las maneras en las que eventos de muerte, relacionados con minería, se convierten en casos de derechos humanos y adquieren o pierden valor, volviéndose relevantes, emblemáticos o simplemente caen en el olvido. En particular, se analizará un caso relacionado con la explotación de carbón en el Cerrejón que se ha vuelto especialmente relevante para organizaciones de derechos humanos, ac-

2 Es importante aclarar que no estoy afirmando con esto que las violaciones a los derechos humanos relacionadas con minería no sean políticas, o que no sean entendidas como políticas por muchos de los actores que se relacionan con ellas. Quiero decir, como intentaré dejar claro más adelante, que tienen unos recorridos y trayectorias jurídico-políticas diferentes que muchas veces escapan los dispositivos institucionales que permiten su legibilidad en determinadas redes de los derechos humanos, y lugares de discusión institucionales, políticos y afectivos. 
tivistas nacionales y extranjeros, agencias de cooperación internacional y otra serie de actores relacionados con la minería en la Guajira.

\section{El valor de la muerte y las redes de derechos humanos}

A nivel global, las prácticas, discursos e instituciones de los derechos humanos se han convertido en un lugar privilegiado de acción e intervención política para movimientos sociales, activistas y ONG. Es innegable que su importancia contemporánea ha redefinido lo que significa la actividad política en muchos lugares del planeta. Precisamente, porque su relevancia no puede ser desdeñada, es crucial reflexionar acerca de los diferentes procesos que han llevado a que el marco normativo y moral de los derechos humanos se haya convertido en privilegiado, así como lo que ha sucedido con otros horizontes de acción e imaginación política. Sobre todo, es importante estudiar qué ha significado la hegemonía de los derechos humanos como lugar de acción política para movimientos, activistas y proyectos políticos que se plantean como alternativos al orden de poder que existe.

En América Latina, aunque no exclusivamente, los activistas se han convertido en expertos en los laberintos jurídicos, políticos y morales de los derechos humanos. Con esto se quiere señalar, que los derechos humanos han superado el lugar restrictivo del conocimiento vernáculo de los expertos, para ser usado de múltiples maneras por campesinos, indígenas, comunidades afro, trabajadoras de fábricas y una multitud de actores políticos, cuya autoridad no está determinada por su profesionalización y validación en las esferas de la experticia del derecho o de los derechos humanos (Merry, 2006). Esto se debe, en buena medida, al uso que desde los años setenta se ha hecho de ellos como forma de protección de la vida en contextos de represión. Han sido varios los autores que en los últimos veinte años han estudiado este fenómeno desde múltiples perspectivas, algunos más críticos que otros, pero, en general, comparten la idea de que las instituciones, prácticas y discursos de los derechos humanos se convirtieron en una herramienta más o menos efectiva para hacer frente a las múltiples formas de violencia 
política que se empezaron a dar en América Latina desde la guerra fría (Jelin, 2003; Theidon, 2012; Sanford, 2000).

Autoras como Keck y Sikkink (1998) se han concentrado en estudiar la forma en que las luchas por la defensa de los derechos humanos, han producido redes transnacionales que se vuelven cruciales para ejercer, de manera eficaz, el activismo relacionado con los derechos humanos. Desde pequeños colectivos de solidaridad, pasando por ONG, cortes internacionales, grupos de abogados, académicos y medios de comunicación de diversa capacidad de circulación, las redes de derechos humanos son importantes porque permiten traspasar las fronteras y llevar eventos de violencia y represión a instancias que tienen la capacidad de hacer presión moral y política a los grupos que han ejercido la violencia, como una forma de mantener las órdenes de poderes determinados. Las autoras se concentran en la represión por parte de algunos Estados latinoamericanos durante la guerra fría. La imposibilidad de los activistas de obtener respuesta sobre la violencia política por parte de los entes oficiales nacionales, los obligó a ir más allá de los límites del Estado nacional e hizo necesaria la presión internacional, ejercida a través de dispositivos legales, morales y políticos. La expectativa, al ir más allá de los Estados nacionales para denunciar las prácticas de terror locales, era lograr que la presión internacional fuera capaz de transformar las políticas estatales. Esta táctica, que las autoras denominan efecto boomerang, se ha convertido en una forma estándar de acción por parte de quienes hacen parte de las redes globales de los derechos humanos, y en esa medida, sugieren que las luchas por la defensa de los derechos humanos nacen, en una parte importante, a través de esas redes de solidaridad, apoyo y litigio transnacional.

La presencia activa de ONG, coaliciones y movimientos colombianos en las redes globales de derechos humanos no solo ha permitido la circulación de experiencias de violencia nacionales en otras geografías, sino que además ha convertido a estas redes en actores de negociación política con impactos concretos en Colombia. Puesto en términos esque- 
máticos, los eventos de violencia relacionados con derechos humanos circulan, de muchas maneras, en redes locales y trasnacionales: desde testimonios vivos de personas que viajan a contar sus experiencias hasta libros, documentales, reportes de ONG, artículos periodísticos y académicos, canciones y documentos jurídicos. De igual manera, esos eventos de violencia emergen en escenarios específicos como salas de reuniones, conferencias, congresos, juzgados, sets de televisión y radio, universidades y oficinas de agencias de cooperación internacional.

Para los efectos de este escrito, es importante clarificar qué se comprende como "caso". Es común que en las instituciones, prácticas y discursos de los derechos humanos se entienda cualquier violación a los derechos humanos como un caso, precisamente porque se asume a priori que todas las violaciones contra la vida de los seres humanos tienen el mismo valor intrínseco. Como se expuso anteriormente, en este texto se tomará una ruta diferente, que implica entender el valor de las vidas a través de prácticas sociales y materiales concretas, en las cuales se articulan los elementos que van moldeando la importancia de un evento de muerte. Por eso, se considera importante hacer una distinción entre el evento de muerte (sea este un asesinato, una desaparición o la degradación paulatina de la vida), que es lo que usualmente se entiende como algo digno de ser un "caso" de derechos humanos, y los ensamblajes materiales, políticos, morales $\mathrm{y}$ afectivos que hacen posible que un evento de muerte se convierta en un caso de derechos humanos. Dicho de otra manera, una situación de violencia no se convierte en un "caso" por el hecho de existir, es decir, porque haya sucedido. Por el contrario, para que se vuelva "caso”, ese evento tiene que convertirse en muchas otras cosas, desde objetos (como papeles que son demandas y tutelas) hasta recuerdos que se presentan en videos por YouTube, entrevistas que se vuelven artículos de prensa y redes de afecto y solidaridad que reconocen determinada experiencia de violencia como algo importante en un momento determinado.

Hacer una lista de las formas posibles que toma un "caso" para su circulación o los lugares en los que hace presencia busca, sobre todo, dar cuenta de la vastedad de las redes y los múltiples lugares en los 
que circulan los “casos”. Sin embargo, también tiene como intención enunciar algo que es relevante para este escrito: un evento de violencia se vuelve "caso" y adquiere valor precisamente en la circulación que tiene en las redes de los derechos humanos. La muerte o la violencia no definen por sí mismas su conformación como “casos” en las redes de derechos humanos, pues no hay ninguna condición intrínseca o natural a la muerte o la violencia. De igual manera, para que un evento de muerte se convierta en un "caso" de derechos humanos, no puede restringirse exclusivamente al lugar donde sucedió esa muerte; las posibilidades de convertirse en un "caso" relevante, reconocido y valorado dependen, en buena medida, de las formas en las que se ensambla una y otra vez, para aparecer en las redes transnacionales de los derechos humanos (o lo contrario).

Por todo lo anterior, la idea de "caso", en este artículo, no se restringe a su dimensión jurídica, sino a las múltiples maneras en que se codifica, se articula y se ensambla el evento en una variedad de artefactos que permiten su circulación en diversos escenarios, en donde adquiere o no valor.

Se hacen estas aclaraciones para tomar distancia de la premisa generalizada de las prácticas e instituciones de derechos humanos que sostiene su estatus moral y, de alguna manera, la fuerza de su legitimidad. Esa premisa habla de la sacralidad de la vida y el carácter universal de los derechos humanos que incluye, por lo tanto, a todos los seres humanos. En primer lugar, la crítica que emerge desde lecturas como las de Agamben (1998) a los derechos humanos, se concentra en la idea de que la vida es sagrada y termina por defenderla hasta el punto de no cuestionar las condiciones de brutal opresión a las que puede ser sometida. Para este autor, la vida desnuda supone una radical despolitización de la comprensión de las condiciones de existencia, al punto en que las circunstancias que producen vidas precarias y frágiles son desconocidas para una idea de la vida que es poco más que el acto de respirar y tener los ojos abiertos. De ahí que, por ejemplo, la crítica al 
humanitarismo que pone el acento en cómo el aliviar el sufrimiento puede reproducir la desigualdad sin cuestionar las condiciones que generan ese sufrimiento (Fassin, 2007; Ticktin, 2011).

En segundo lugar, el universalismo abstracto de los derechos humanos supone la despolitización y deshistorización de los procesos que definieron la categoría "humano". Como varios autores lo han expuesto (Asad, 2000; Moyn, 2009; Douzinas, 2000; Mignolo, 2009), esa noción en los derechos humanos ha sido organizada alrededor de una experiencia histórica particular, en donde las posturas morales y las expectativas del liberalismo priman. La consolidación de los derechos humanos como parte del ethos liberal supone una configuración específica de las relaciones políticas, de lo que se entiende como humano y de las jerarquías que organizan los grados de humanidad. De otra parte, la misma premisa asume en términos abstractos que todas las muertes relacionadas con los derechos humanos tienen el mismo valor, precisamente, con relación a las consideraciones morales que sustentan las prácticas, discursos e instituciones de los derechos humanos.

Contrario a esa afirmación, en este trabajo se plantea que los eventos y las formas de la muerte adquieren relevancia por una serie de articulaciones materiales, políticas y afectivas que van definiendo qué muerte o qué formas de la muerte son más importantes. El valor de la muerte, por lo tanto, no está predefinido, sino que, como lo afirman autores como Graeber (2001), Ferry (2013) o Verdery (2003), se produce a través de las relaciones materiales concretas, donde la categoría valor no puede serle adscrita a un objeto por sus características intrínsecas, sino por el tipo de relaciones que establece, por los lugares en donde se presenta y por las redes de las que hace parte.

El valor de la muerte en los derechos humanos no es sustancialmente diferente. No todas las muertes tienen igual valor. Hay asesinatos políticos que no adquieren importancia, mientras que otros de características similares se vuelven importantes; hay aspectos de las víctimas 
que pueden ser relevantes en momentos determinados por razones políticas contingentes (el asesinato de un sindicalista en un momento en que se negocia un TLC) y luego desaparecer; situaciones específicas en países europeos con presencia en Colombia, en términos de ayuda internacional, pueden llevar a que ciertos casos y ciertas regiones se activen como importantes en detrimento de otros; a veces, relaciones afectivas con otras organizaciones o con personas llevan a que se busque que un caso se vuelva relevante.

Las situaciones que llevan a que un evento de violación a los derechos humanos sea registrado moral y políticamente como un caso de derechos humanos - de hecho, a que sea registrado como parte del campo de los derechos humanos - son diversas y, como dije anteriormente, no dependen exclusivamente del evento específico de violencia. En esa medida, este texto se distancia de la premisa de los derechos humanos que supone que todas las muertes tienen el mismo valor, dado el universalismo humanista de los discursos, prácticas e instituciones de los derechos humanos, para, por el contrario, plantear que el valor de un caso depende de trayectorias históricas, conflictos, disposiciones afectivas, políticas y articulaciones materiales en redes transnacionales.

\section{De las formas de la muerte y su captura}

Quienes tienen una postura crítica de los derechos humanos suelen argumentar que su consolidación hegemónica ha desplazado discusiones en torno a las condiciones político-económicas de la desigualdad, privilegiando la idea de que la defensa de las libertades democráticas debe ser el eje de las discusiones y objetivos. A pesar de que -como lo han anotado distintos autores - las discusiones en torno a los límites y posibilidades de los derechos humanos han impulsado una expansión importante de los objetivos que se encierran en el marco normativo y moral de los derechos a escala global, ha sido particularmente difícil articular las esferas de la economía y los derechos de manera consistente (Sassen, 2006; González, 2014). Uno de los ejemplos más claros de las 
consecuencias de la brecha entre regulaciones legales a escala global y la esfera de la economía se encuentra, precisamente, en la discusión alrededor de la naturaleza.

Aun cuando en los últimos años los debates en torno a los límites de los derechos humanos han terminado por expandir de manera importante su campo de intervención -abriendo escenarios de reconocimiento alrededor de temas como la alimentación y la identidad étnica (Edelman, 2014; Charters y Stavenhagen, 2009) - , es claro que aún no hay suficientes herramientas de acción que permitan, por ejemplo, regular de manera efectiva las acciones de empresas transnacionales o los daños ambientales que generan.

De lo anterior se desprenden varias cosas: la primera es que la introducción eficaz de la naturaleza en las discusiones en torno a los derechos sea aún incipiente y limitada, en parte porque el lugar de la naturaleza implica discutir su uso como recurso económico, es decir, como materia que se apropia y se transforma en capital; la segunda es que en los eventos de muerte relacionados con recursos naturales, no es poco común que las causas político-económicas relacionadas con la naturaleza (por ejemplo, el extractivismo) sean subordinadas a otros elementos que tienen mayor efectividad jurídica y moral —como imágenes de sufrimiento, asesinatos o formas de violencia política-; la tercera es que existen dificultades claras para dar cuenta de las diferentes modalidades de la muerte y darles estatus equivalentes.

Lo anterior no significa que la categoría naturaleza no esté siendo profundamente redefinida en los circuitos jurídicos y políticos donde los expertos de ONG y activistas de organizaciones sociales circulan. Por el contrario, el esfuerzo que implica introducir la naturaleza en los conflictos políticos y jurídicos es evidente y, aunque no es motivo de este escrito, es parte de una importante reorganización epistémica en la que la naturaleza se convierte en una categoría en conflicto. Sin embargo, lo que interesa resaltar aquí es como la naturaleza es un lugar de 
disputa jurídico-político; las estrategias y tácticas para hacer frente a las violaciones a los derechos humanos relacionadas con el extractivismo aún no han sido estabilizadas. Por el contrario, en varias ocasiones no tienen capacidad vinculante o simplemente no existe una normatividad transnacional que permita el mismo tipo de ejercicio boomerang que existe con otras formas de violación a los derechos humanos.

Por lo anterior, las formas de actuación de los activistas y expertos, cuando están motivadas por las violaciones a los derechos humanos y su relación con el extractivismo, deben ser redefinidas cuidadosamente. No todos los eventos-situaciones sirven para convertirse en casos a nivel nacional y transnacional, aunque en ocasiones la proliferación de casos permite la construcción de una imagen general en torno a las prácticas de los responsables, ya sean privados o estatales. Igualmente, y dependiendo del enfoque, diferentes organizaciones tienen diferentes maneras de aproximarse a la relación entre minería y derechos humanos. Una ONG de abogados puede definir el tipo de casos a trabajar en función del potencial que tiene el caso a nivel jurídico para generar un impacto transnacional. Por eso, dependiendo de las directrices de la organización, de las relaciones de la ONG con agencias de cooperación y de los mismos objetivos éticos y políticos, así como de relaciones afectivas emergentes, diferentes oNG definen casos y las formas que estos adquieren.

Hay ONG que privilegian la intervención en agencias multilaterales, cortes internacionales y lugares de toma de decisión transnacional. Algunas consideran que es el plano del litigio el más relevante, mientras otras entienden que son las estrategias políticas, afectivas y organizativas las que alimentan el litigio. Por otra parte, un colectivo ambientalista no necesariamente tiene entre sus objetivos el plano jurídico, aun cuando se puedan generar alianzas con grupos de abogados y tengan un trabajo transnacional articulado. Por lo tanto, realizan otro tipo de intervenciones en las que el trabajo jurídico no es central. 
Lo cierto es que jurídica, política y moralmente suele ser más fácil organizar casos de derechos humanos que se puedan entender a través de eventos concretos, que puedan ser capturados por los diferentes dispositivos que producen los casos. Asesinatos, masacres, desapariciones y desplazamientos son eventos extraordinarios que irrumpen la cotidianidad, que se entienden como espectaculares y que articulan conflictos políticos hasta el punto de poder enunciar las relaciones de poder que generan esas formas de muerte. Como eventos extraordinarios, aun cuando estén envueltos en velos de impunidad, los dispositivos jurídicos, institucionales y morales de los derechos humanos hacen mucho más fácil que esos eventos se capturen en diferentes medios que permiten su circulación transnacional; es decir, que se conviertan en casos que circulan tanto en su forma jurídica como a través de documentos, reportes, entrevistas, documentales, artículos y otro tipo de objetos.

Sin embargo, existen otras formas de morir, o mejor, modalidades de la muerte que tienen otras temporalidades, velocidades y desarrollos. En particular, me refiero a aquellas formas de la muerte que no son espectaculares, extraordinarias o inmediatas, sino que se caracterizan por estar distribuidas en el tiempo, por ser mundanas, por ser una constante en la vida cotidiana como si de alguna manera fueran muertes sedimentadas que van afectando rutinariamente la vida hasta desparecerla y, paradójicamente, fundirse temporalmente con ella. Esas formas de morir, que algunos llaman "slow death" (Berlant, 2007), y que otros definen como "slow violence” (Nixon, 2011), expresan una degradación paulatina de la vida que termina haciendo parte de ella y que, en el caso de este escrito, también hace parte de situaciones explicitas donde los efectos ambientales de la apropiación de la naturaleza terminan por degradar la vida hasta extinguirla. A diferencia de los eventos extraordinarios e inmediatos, la violencia lenta se extiende en el tiempo y escapa a las formas tradicionales de captura por parte de los dispositivos jurídicos, políticos y morales de los derechos humanos. La "violencia lenta”, que se expresa en situaciones como el polvo de carbón en regiones mineras, la contaminación del agua o su acaparamiento y las 
masivas reconfiguraciones de las geografías producto de la explotación de minerales son, desafortunadamente, mucho más difíciles de ensamblar como "casos".

En sí misma, la muerte lenta es un lugar de conflicto de autoridades políticas, científicas y materiales ${ }^{3}$. Ya sea en la India, Perú, Nueva Guinea o Colombia, los daños ambientales y sus efectos sobre la vida de las personas tienden a ser objeto de reclamo por parte de comunidades y activistas que, las empresas y el Estado se empeñan en desvirtuar. Las formas lentas de la muerte en ocasiones ni si quiera pueden ser registradas como muerte o violencia para las redes, actores y legislación de los derechos humanos, es decir, aún su definición como evento o experiencia está en disputa. Lo anterior supone un problema práctico que reverbera en el cómo se puede adelantar (o no) un trabajo efectivo en torno a violaciones de derechos humanos en los que la naturaleza tiene un lugar predominante. Aunque no es posible afirmarlo como un axioma definitivo, lo cierto es que, por lo menos en su dimensión jurídica, suele ser más fácil llevar un caso de una muerte inmediata (un asesinato, por ejemplo), que uno de una muerte lenta. Esto es algo que ha sido reiterado por diferentes actores que han trabajado tanto en el campo de los derechos humanos, quienes se encuentran relacionados con temas de violencia política, es decir, con formas de violencia lenta que están directamente emparentadas con temas ambientales.

Como se expuso anteriormente, la misma idea de la muerte es cuestionada en la violencia lenta. El terreno jurídico-político, así como la autoridad científica, que valida las pruebas de la muerte, son inestables. La relación entre la degradación paulatina de la vida, las condiciones

3 Con autoridades me refiero tanto a los actores que producen la autoridad del hecho científico como a las formas en que entran en conflicto los diferentes hechos científicos para alcanzar un estatus de autoridad determinado que se imponga sobre otros. 
materiales que generan esa degradación y la posibilidad de traducirlos en "casos” jurídicos es especialmente frágil, porque la conexión entre la muerte y sus posibles causas como consecuencia del deterioro ambiental se pone, constantemente, en duda. Ahora bien, enunciar estos problemas, hablando de "causas ambientales", puede llevar a mistificaciones que terminan por esconder problemas históricos y materiales concretos. La degradación ambiental no es abstracta, sino que tiene responsabilidades puntuales, producto de relaciones con la naturaleza y maneras específicas de entenderla. La división ontológica entre naturaleza y cultura o entre humano y no humano ha operado, de forma tal, que presupone la existencia de la naturaleza como un objeto que deber ser apropiado y subordinad por la humanidad. Como sugieren varios autores, la producción de la naturaleza como un campo ontológicamente diferenciado de lo humano ha sido fundamental para su apropiación en la acumulación de capital y reproducción del capitalismo (Foster, 2000; Smith, 2010).

En ese orden de ideas, la afirmación abstracta "causas ambientales" es constantemente refutada y puesta en duda por parte de empresas y agentes gubernamentales. Hablar de causas ambientales es una práctica bastante común por parte de actores que entienden la naturaleza como un campo ontológicamente diferenciado de lo humano y, por lo tanto, subordinado a este. Las "causas ambientales" se entienden como un problema que parte de la distinción entre la naturaleza y lo humano, en donde lo segundo siempre ha subordinado y dominado lo primero. Desde esa perspectiva, el problema se articula alrededor de la mitigación del daño ambiental, para mantener la apropiación de la naturaleza y minimizar los efectos sobre las personas. Esa manera de entender la explotación minera reafirma la subordinación de la naturaleza a lo humano y la división ontológica entre ambos campos, como eje principal de la idea sobre la propiedad de la naturaleza. (Moore, 2011).

Por lo tanto, el enfoque de la discusión no es, necesariamente, que existan daños ambientales, pues las empresas han reconocido, en los 
últimos años, los impactos ambientales que han causado al ambiente y han generado una variedad de dispositivos, diseñados para solucionar o limitar los efectos de la extracción ${ }^{4}$. La discusión gira en torno a la eficacia de las medidas tomadas por las empresas, la magnitud de los daños y la intensidad con que se afecta la vida de las personas. Dicho de otra manera, el punto en discusión no es si existen o no efectos ambientales, producto de la explotación minera, sino si las regulaciones empresariales, el seguimiento gubernamental y su implementación son realmente suficientes para garantizar mínimas condiciones de vida de las personas en lugares relacionados con la extracción de recursos minerales.

\section{Datos en disputa}

Muchos autores se han concentrado en la manera como se definen los efectos de la explotación de la naturaleza, exponiendo cómo la autoridad de los hechos depende de multiplicidad de disposiciones, disputas, e intenciones que producen de diferentes maneras el hecho científico y su validez (Bijker et al., 2009; Li, 2015; Latour, 2013). En su trabajo sobre las disputas alrededor del petróleo en Ecuador, Fiske (2016) narra como la recolección de muestras en diferentes lugares donde había explotación daba resultados contradictorios que podían ser usados por las partes para justificar sus argumentos, es decir, para darles validez científica. Como ella lo describe, la expectativa ante los resultados científicos es rápidamente desmantelada, no por inconsistencias o falta de rigurosidad, sino porque los procesos de recolección de muestras eran diferentes.

4 Aunque no es el centro de este texto, es importante anotar que la emergencia en los últimos años de las críticas globales a las prácticas empresariales ha generado un crisol de fundaciones, mandatos, lineamientos y debates en torno a cómo garantizar las buenas prácticas de las empresas. Aunque hay iniciativas al respecto, hasta ahora ninguno de los mecanismos creados tiene un carácter vinculante. 
En esa medida, la decisión sobre qué se acepta como un hecho científico, su autoridad, está mediada por consideraciones políticas muy diversas que llevan a resultados jurídicos radicalmente distintos. Lo anterior no es especialmente novedoso, si asumimos que los estudios sociales de la ciencia han expuesto hace mucho el carácter político de la construcción de la autoridad científica. Sin embargo, en el caso estudiado por Fiske en Ecuador, los resultados que ofrecen los procedimientos científicos resuelven muy poco en la disputa sobre la responsabilidad de la empresa frente a los daños ambientales y, por lo tanto, el valor de las pruebas es siempre susceptible de ser cuestionado.

Esa es, precisamente, la situación en la que se encuentran Nora y su hijo. Como parte de la comunidad wayuu de Provincial en La Guajira, Nora estuvo presente en el proceso de fortalecimiento organizativo que varias ONG colombianas adelantaron por varios años, centrado fundamentalmente en los efectos que tenía la explotación de carbón de la mina Cerrejón, tanto en las diferentes comunidades aledañas a la mina como en las transformaciones geográficas que la explotación generaba. Ese proceso se terminó en 2015 debido a que varios líderes de las comunidades pactaron unilateralmente con la empresa.

Las razones que llevaron a esa decisión, sus efectos y lo que ha sucedido con esa relación no son motivo de profundización de este texto. No obstante, es importante situar el devenir del caso de Nora en ese contexto, pues es muy difícil entenderlo sin ello. La fractura "relativa"5 de las ONG bogotanas con la comunidad de Provincial significó un golpe tanto político como emocional para las personas involucradas, pues habían puesto una parte importante de sus energías en la querella que Provincial tenía con Cerrejón. La decisión de Nora de mantenerse en la disputa con Cerrejón fue, según cuentan quienes han estado pre-

5 Relativa, porque aunque hubo un rompimiento fuerte, aún existen habitantes de Provincial que se reúnen con estas ONG que están dispuestos a continuar con sus demandas, en un trabajo colaborativo con las expertas de dichas organizaciones. 
sentes, desconcertante y confusa. Era difícil entender por qué Nora podría tomar una decisión de estas características, cuando el resultado inmediato sería el ostracismo y la marginalización, por no hablar de la precarización de sus condiciones de vida, en un contexto en el que Cerrejón provee de manera importante las posibilidades de existencia de las personas cercanas a la mina ${ }^{6}$.

Sin embargo, en medio de la ruptura oficial de la relación de las ONG con Provincial, se tomó la decisión de establecer una relación directa con Nora y adelantar un proceso jurídico. Según Nora, la salud de su hijo era una prioridad que la obligaba a tomar la decisión de mantener una disputa con Cerrejón, aun cuando eso significara ir en contra de las decisiones de Provincial y sus autoridades. La razón de su argumentación es, relativamente, transparente. Desde que su hijo nació ha tenido problemas para respirar; ella está segura que esto se debe a la cercanía que tiene su vivienda con Cerrejón. En particular, sabe que es el efecto del polvo de carbón que se levanta regularmente en toda la zona por las múltiples prácticas de la extracción del mineral. Sabe también que su hijo no es el único que sufre esta situación, sino que es un problema generalizado de los pobladores de los lugares cercanos a Cerrejón. Se hace énfasis en la palabra "sabe” porque la certeza tanto de Nora como de quienes la han acompañado, acerca de las razones de la enfermedad de su hijo, es una buena parte de los motivos que impulsan el trabajo y la constancia de los abogados, académicos y expertos de ONG.

Aunque no se puede asegurar que su interés inicial haya tenido en cuenta una dimensión colectiva, lo cierto es que para el momento en que se inició este trabajo de campo, Nora no hablaba exclusivamente de su hijo, sino que situaba su experiencia como una suerte de catalizador

6 Aunque no es motivo de este escrito, es importante anotar que las comunidades, pueblos y veredas cercanas a Cerrejón dependen de manera importante de la mina, ya sea como obreros de la mina, como transportadores de material o personas, como burócratas en el Estado, como dueños de tiendas, hoteles y otros negocios. 
de un problema generalizado que no era reconocido como importante. Esto es relevante porque habla de dos temas: primero, los efectos que en Nora ha tenido relacionarse con múltiples audiencias, obligando a presentar de diferentes maneras su experiencia y buscando, al mismo tiempo, darle un carácter político que se extienda más allá de sus objetivos personales; segundo, los aprendizajes políticos que su circulación en escenarios de debate y discusión de la minería, han alimentado la presentación del caso. Nora no era, en principio, una líder wayuu o de Provincial. Aunque varias organizaciones de la Guajira simpatizan con sus objetivos, no es usualmente entendida como una representantelíder, sino más bien como una mujer "de la comunidad"7. Esto la sitúa en un umbral, que le permite al mismo tiempo cierta movilidad que, de otro, modo no tendría. La idea de que no es líder, en el sentido en que en Colombia generalmente se entiende el término, supone que no está inmersa en ciertas discusiones políticas, es decir, que su presencia y quehacer no tienen segundas intenciones.

La ruptura de las ONG con Provincial dejó en suspenso varios proyectos y proyecciones políticas. Las discusiones con Cerrejón en torno a su responsabilidad ambiental, si bien no se frenaron, sí debieron ser transformadas. El hecho de enfocarse en un caso formalmente individual, luego de trabajar en uno colectivo, hizo necesario reformular las estrategias jurídicas y políticas con las que se venía operando. El caso de Nora es una instancia más dentro de una red de situaciones, conflictos y eventos en la Guajira, que en ocasiones se convierten en "casos” jurídicos con determinado estatus legal, político y moral. La extensión de Cerrejón involucra una gran variedad de escenarios de conflicto que incluyen reasentamientos, disputas ambientales, por el agua y transformaciones

7 Uso las comillas para enfatizar que la frase implica una conceptualización que define un cuerpo político colectivo. La frase "la comunidad" es usualmente usada tanto por líderes de organizaciones como por militantes de base, movimientos sociales y expertos de ONG para enunciar un cuerpo político imaginado a través de identidades territoriales, étnicas o de género y que permiten, sobre todo, su enunciación en escenarios diversos de preparación organizativa, debate o disputa. 
en la geografía y el paisaje. Nora hace parte también de un ensamblaje estratégico en formación, aunque no totalmente consolidado. Vale decir también que la red de organizaciones, que trabaja con temas relacionados con minería en La Guajira, se extiende y se contrae de acuerdo a múltiples situaciones contingentes, y que, aunque no es el objetivo de este documento, es necesario aclarar que son muchas las organizaciones que trabajan temas relacionados con minería y derechos humanos, y que de una manera u otra, se han encontrado con el caso de Nora.

Diferentes organizaciones trabajan en una campaña internacional llamada "La Guajira le habla al país". La campaña funciona como una sombrilla estratégica que permite articular múltiples situaciones de la región, aunque no es una campaña constante, sino más bien en formación. La forma en que está diseñada permite a quienes hacen parte de ella realizar acciones que se inscriben como parte de "La Guajira le habla al país”. Aunque cada organización trabaja en casos y situaciones diferentes, al enmarcarlos en una campaña se articulan de manera que se presenta una perspectiva integral sobre violaciones a derechos humanos, reasentamientos, acaparamiento de agua y desvíos de fuentes hídricas para expandir el radio de extracción de carbón. La decisión sobre qué casos son usados en las campañas tiene tanto de contingente como de estratégico, es decir, depende de los conflictos socio-ambientales de la región y de las prioridades que las ONG definen en torno a la eficacia posible del caso, la magnitud del problema, la capacidad de convertirlo en un caso relevante y las posibilidades concretas de llevar disputas políticas y jurídicas a buen término.

Nora representa un caso paradigmático en los diferentes conflictos que definen a La Guajira como un departamento con serios problemas por la minería. Los elementos de género y étnicos tienen un peso específico como piezas dentro del rompecabezas minero de ese departamento. La particularidad de su caso, es decir, el problema puntual de su hijo enfermo, también se añade a las características de la situación. Aunque inevitablemente esos elementos orientan las discusiones en torno a 
Nora y los problemas de salud, la decisión de tomar el caso por las abogadas no respondió a un cálculo en el que esto fuera definitivo. Como fue mencionado anteriormente, fue el hecho de que Nora decidiera mantener una disputa con Cerrejón, más allá de las determinaciones de su comunidad, lo que llevó a tomar la decisión de hacerse con el caso.

\section{Imágenes de la muerte en disputa}

Provincial queda a veinte minutos del pueblo de Barrancas, en la parte baja de La Guajira. Después de viajar unos minutos por la carretera principal, hay que entrar por un camino destapado hasta entrar al resguardo. Una vez ahí, una carretera hecha en piedra, por donde transitan personas, camiones, motos y carros, nos conduce a la casa de Nora, que está al lado del camino en piedra, desde donde es posible ver los tajos de la explotación de Cerrejón. El paisaje no tiene muchas tonalidades. Casi todo es de un color amarillento, muy similar en la tierra y en las casas de barro. Hay basura en muchos lugares. Bolsas de plástico que alguna vez volaron y se quedaron atrapadas entre los árboles y los cactus. Los árboles no tienen hojas. Sus troncos y sus ramas son indefectiblemente negros, como si hubieran sido pasados por el fuego. La tierra está quebrada, la falta de agua está presente en cada rastro del paisaje, en cada conexión vital que existe entre las casas, los árboles, la basura, los animales y las personas.

Al fondo está Cerrejón que, según los pobladores de Provincial, recientemente expandió su explotación de carbón mucho más cerca del resguardo. La casa en la cual vive Nora con sus tres hijos y su esposo no es la misma que tenía hace años. Esta fue construida con diversos materiales por un grupo de personas que trabaja la permacultura. Ellos visitaron el lugar y diseñaron una casa que se ciñera a los deseos de quienes la habitarían, añadiéndole algunos elementos distintivos, como más ventanas para la entrada del aire —ocho, dice con orgullo el esposo de Nora- y detalles decorativos hechos con botellas incrustadas en las paredes. Nora y su esposo decidieron pintarla de blanco, lo que le 
da un aire distinto, aunque para quienes conocieron la casa originalmente el nuevo color rompe un poco con la idea con que se construyó.

La casa donde originalmente vivían es adyacente a la nueva. Las grietas son visibles en las paredes y ayudan a entender por qué ya no están ahí, por qué necesitaban de una nueva vivienda. Según varias personas, los cimientos de esa primera casa no eran los mejores, pero a eso hay que sumarle los efectos de las explosiones de Cerrejón, que suceden todos los días a las 2:30 de la tarde. Es difícil escapar a la rudeza de este paisaje, a la restringida paleta de colores: gris y negro en los tajos al fondo, amarillo en las casas, la tierra, las lomas y ese negro ceniza de los árboles. El polvillo de carbón — partículas suspendidas - pinta los objetos con sutileza, como acariciándolos. Sillas, canecas, ollas, mesas y casas tienen una ligera capa del polvillo. Dicen quienes habitan las zonas cercanas a Cerrejón que las explosiones levantan el polvo que empieza a flotar por toda la región y causa diversas molestias, que van desde ardor en los ojos hasta problemas para respirar. El efecto del polvo en los pulmones es el principal problema que afecta al hijo de Nora, quien para el momento de escribir este texto tiene tres años.

Las personas que viven cerca de Cerrejón hablan de los efectos de las prácticas de extracción en la mina en sus cuerpos y en sus vidas. El polvillo de carbón y los problemas que genera es tan solo uno de los temas que los habitantes reconocen como parte del daño. Ellos cuentan los efectos en sus vidas y, a través de esas narraciones y de la forma en que circulan, adquieren un estatus de verdad en los caseríos y pueblos de la región. Por su parte, Cerrejón responde con estudios científicos, con ingenieros, biólogos y otro tipo de expertos que invalidan los reclamos de quienes habitan alrededor de la mina. Es precisamente en ese terreno de disputa que la discusión en torno a la vida del hijo de Nora emerge como una suerte de dispositivo que cataliza disputas de saber, procedimientos jurídicos, estrategias morales y afectivas, así como un terreno de disputa entre saberes y proyectos políticos en torno al futuro de la minería en Colombia. 
Son muchos los autores que se han concentrado en las formas en que se ejerce la autoridad científica, se hace énfasis en la prueba de las evidencias, los hechos y los datos que adquieren estatus de verdad ( $\mathrm{Au}$ yero y Swiston 2007; Graeter 2016; Brown 1992). La diferencia entre la experiencia sensorial y el conocimiento experto, validado por la autoridad científica, se encuentra en el centro de las disputas. En diferentes asentamientos alrededor de Cerrejón, los habitantes hablan de las explosiones, del polvo de carbón y de la contaminación del agua. También hablan de cómo sus percepciones de estas situaciones son invalidadas por el saber de los ingenieros y biólogos contratados por Cerrejón, quienes a través de datos, conceptos y presentaciones demuestran, como ha sido sostenido repetidamente, “que no pasa nada y todo está bien”. La forma en que se desactiva cualquier posibilidad de crítica, a través de la autoridad del saber "experto" deja constantemente en jaque tanto a habitantes como a movimientos sociales y ONG.

La propuesta de Latour (2005) de ubicar las preguntas de investigación, no en los matters of fact sino en los matters of concern, apela a considerar las formas, en las que se producen los hechos científicos, como prácticas concretas donde múltiples actores entran en relación para producir un hecho determinado. Como sugiere Fiske (2016), la evidencia validada a través de procedimientos científicos no es simplemente un algo que se descubre, sino más bien algo que se ensambla en las redes de actores y formas de conocimiento experto. La diferencia entre los aspectos sensoriales que llevan a los habitantes cercanos a la mina de Cerrejón a afirmar la existencia de daños concretos en sus vidas, y la validez que pueden adquirir en ámbitos legales, está mediada por los múltiples factores científicos, afectivos y políticos que les dan legitimidad a unos sobre otros.

Desde hace varios años, la discusión en torno a los efectos nocivos del polvillo de carbón en la Guajira hace parte de la vida cotidiana de la mina. Hay organizaciones de trabajadores que propenden por la salud en el trabajo, así como un debate constante en torno a si el grado de 
afectación de los niveles de macropartículas son suficientes para hablar de una contaminación que amenaza la salud humana. En este reclamo han participado entes estatales, académicos, grupos de solidaridad internacional, ONG y varios actores privados. Sin embargo, no hay una respuesta definitiva, aun cuando cada situación está sustentada por diferentes procedimientos que buscan darle el estatus de validez que merece. La discusión se ha dado, principalmente, en torno a las formas de medición de la calidad del aire y de los estándares nacionales e internacionales al respecto.

Aunque el debate no ha concluido, el informe del Cinep sobre el carbón en La Guajira es un punto de inflexión interesante. En dicho informe, de 2012, el Cinep llevó a cabo una serie de cuestionamientos a los diferentes impactos del carbón. En el apartado concerniente al aire argumenta que, a pesar de que Cerrejón cumple con los requerimientos nacionales, no se puede considerar esto como una garantía para su funcionamiento. A su turno, Cerrejón afirmó que no solo cumple con los estándares requeridos, sino que es transparente en la presentación pública de la información relacionada con las mediciones de la calidad del aire, es decir, que los resultados de las mediciones pueden ser encontrados en bases de datos sobre la calidad del aire, Sisaire ${ }^{8}$.

Por su parte, quienes han trabajado en este problema plantean otra discusión. Para ellos, en particular abogados, biólogos y geólogos que no están de acuerdo con Cerrejón, hay tres puntos clave en este problema: el primero señala que la regulación estatal es particularmente laxa, sobre todo si se compara con estándares internacionales y los requerimientos de la OMS. El segundo afirma que las mediciones que hace Cerrejón son inútiles, pues la empresa mide material particulado menor a diez micras (PM10), cuando debería medir (PM 2,5), es decir, mucho más fino. La diferencia entre ambas, según los críticos, es que los efectos nocivos para la salud son resultado

8 Respuesta pública de Cerrejón al informe de Cinep (Cerrejón, Junio 28 2016) 
de las partículas más finas, es decir, $(\mathrm{PM} 2,5)^{9}$. El tercero muestra que los puestos de medición se apagan en momentos clave, lo que permite hacer mediciones favorables para Cerrejón.

Todos estos argumentos se esgrimen una y otra vez en reuniones de oficina, seminarios académicos, entrevistas, reportes, artículos y visitas a los asentamientos cercanos a la mina. Ninguno es definitivo, más bien hacen parte de un terreno de conflicto, un escenario de discusión e indeterminación que recorre y conecta diferentes nodos sobre los temas ambientales relacionados con Cerrejón. Los datos, las cifras, las estadísticas y la búsqueda de los diferentes actores sirven para aterrizar y convertir estas preocupaciones en certezas científicas, se convierten en el sustento de las disputas jurídicas.

Ahora bien, esta no es exclusivamente una disputa jurídica, cuya definición pase por la comparación de la veracidad en los datos. Tampoco, un problema en el que el análisis de las formas de producción de la evidencia y las diferencias entre efectos de verdad definen el valor de un caso. A esto se le deben sumar formas de articulación política y afectiva que producen efectos muchas veces tan o más importantes que la validez de los datos organizados en un documento jurídico. Tanto las organizaciones que acompañan a quienes han sido afectados por la minería de carbón como los habitantes suelen dudar de la validez de la evidencia científica que viene del Estado o de la empresa. En estas dos figuras se cristalizan consideraciones históricamente sedimentadas en torno a la deshonestidad, la corrupción y la violencia, que generalmente llevan a que cualquier afirmación proveniente de esos lugares se vea con desconfianza. La idea de que el Estado central y la administración departamental van de la mano con los intereses de la empresa presupone que en las actuaciones de estos actores existe, cuando menos, una doble intención.

9 Cerrejón argumenta que según los requerimientos del país, solo debe medir PM 2,5 cuando los niveles de PM10 superan los límites establecidos, y eso no ha sucedido. 
Por lo tanto, enfrentarse a las afirmaciones de la empresa y del Estado implica expandir significativamente el campo de acción. Ensamblar un caso - hacerlo viable y legible como caso- implica entender que el plano jurídico solo puede ser uno de los lugares de intervención y que una victoria ahí no significa, necesariamente, efectos concretos. En el caso que nos atañe, se ha interpuesto una tutela que falló a favor de Nora, aunque ha sido descalificada por la empresa y no hay formas efectivas que lleven a su cumplimiento. El fallo de la tutela es favorable para Nora solo de manera parcial. Aunque se ha reconocido el daño en la salud del hijo de Nora, el cuestionamiento general, que habla de daños colectivos relacionados con la comunidad de Provincial, no ha sido aceptado en última instancia. Como la tutela, es decir, la acción eminentemente jurídica se entiende insuficiente, los actores cercanos a Nora han dispuesto una variedad de acciones de carácter nacional y transnacional, que, de una u otra manera, le han dado relevancia al caso. Desde pequeños clips visuales que se suben a YouTube, realizados por personas no colombianas - y que por lo tanto tienen como objetivo audiencias internacionales (en su mayoría europeas) - , pasando por notas de prensa en diferentes idiomas, hasta giras a Europa en las que Nora ha podido contar lo que implica vivir tan cerca de la mina de Cerrejón.

\section{Conclusión}

Para los abogados y las personas que acompañan a los diferentes asentamientos cercanos a Cerrejón, se ha hecho particularmente evidente que las disputas sobre la validez de los datos, las estadísticas y los estudios no solo se inclinan a favor de la empresa, sino que, de cualquier manera, hacen incierto el terreno de discusión. Las experiencias de los abogados en Colombia han estado centradas históricamente en los temas de derechos humanos, relacionados con la violencia política, que como se ha dicho anteriormente, están saturadas con eventos extraordinarios, con marcas concretas que pueden ser capturadas a través de diferentes dispositivos jurídicos, afectivos y políticos. La 
centralidad de la guerra convierte a los eventos de violencia inmediata en eventos privilegiados para su circulación. Las formas de acción por parte de abogados y activistas que, por décadas, se han relacionado con esas manifestaciones de violencia, también están contempladas para articular como casos, eventos tales como desapariciones, torturas, desplazamientos y asesinatos. Las prácticas de relacionamiento con las víctimas de esas formas de violencia también son específicas. Aunque muchas organizaciones de derechos humanos tienen un contacto relativamente constante con las víctimas de la violencia, producto de la guerra, pues realizan talleres, eventos públicos y producen toda clase de artefactos para la circulación de esas experiencias de violencia; lo cierto es que la condición extraordinaria de la violencia permite la construcción de un camino específico, mediado por regulaciones jurídicas concretas, por disposiciones gubernamentales e internacionales relativamente bien definidas. El hecho de la muerte violenta como un hecho extraordinario e inmediato implica una marca que, aun cuando esté en disputa, es una referencia concreta. Por lo tanto, el deslizamiento progresivo de buena parte de las organizaciones de derechos humanos hacia temas ambientales se encuentra con retos muy grandes que se expresan concretamente en las prácticas de ensamblaje de los casos.

La disputa por los datos es también una carrera por capturar la muerte en la forma de un caso. La vida se va degradando mientras tanto y la ansiedad acerca del futuro también va sofocando a activistas y personas afectadas. La búsqueda por afirmar la veracidad de la muerte a través de datos que puedan ser validados por agencias internacionales, empresas, académicos y entidades gubernamentales expone un profundo vacío en las prácticas de las organizaciones de derechos humanos. Ante todo, es un vacío que no es solo jurídico, sino fundamentalmente práctico. Las organizaciones de derechos humanos en Colombia se han concentrado en entender la muerte en su dimensión más extraordinaria, en los eventos inmediatos que se ejercen puntualmente contra los cuerpos de las personas. Por eso, las formas de muerte lenta que exponen la fragilidad de la vida, se hacen particularmente difíciles de capturar 
a través de mecanismos jurídicos. Dicho de otra manera, un asesinato deja una huella en el tiempo, aun cuando no se conozcan los móviles; cuando la recolección de pruebas vaya dándole una forma determinada a esa huella, el asesinato es un hecho al cual se puede volver. Tiene cierta cualidad irrefutable ${ }^{10}$. La degradación paulatina de la vida, por lo menos en el caso que nos atañe, es siempre indeterminado, es difícil de capturar por los sentidos y elude los dispositivos jurídicos, políticos y afectivos. La duda está presente, su inestabilidad es producto, al mismo tiempo, de lo mundano de su presencia y de la fuerza de la costumbre que se impone al convivir con la muerte.

La brecha que existe entre la esfera económica y las posibilidades de regulación legal fomentan este espacio de incertidumbre. A pesar de que existen disputas internacionales en torno a la necesidad de encontrar mecanismos de regulación de las prácticas empresariales y que los gobiernos nacionales han intentado regular las prácticas de extracción minera, la brecha entre la normatividad legal y prácticas económicas generan un espacio gris de indeterminación, que ha tendido a favorecer a las empresas transnacionales. Si respecto a los Estados, los activistas de derechos humanos han podido ejecutar de manera efectiva el efecto boomerang, logrando que la presión internacional, progresivamente, haya obligado a generar transformaciones locales; en el caso de las empresas transnacionales, el resultado ha sido cuando menos ambiguo. Tal vez por esa razón es que la preocupación por la imagen de las empresas es tan relevante tanto para ellas como para quienes se oponen a sus prácticas. Sin embargo, es claro que la discusión sobre la imagen tiene un límite concreto y la eficacia relativa de las acciones jurídicas se estrella con la amplia brecha entre lo jurídico y lo económico. En medio de eso se encuentran las expectativas de la fuerza de la organización y

10 Por supuesto, este no es el caso de todas las formas de violencia política. La desaparición forzada, aun cuando fue reconocida como delito en el 2000, es aún un acto que puede mantenerse en la incertidumbre. 
movilización política, así como la degradación paulatina de la vida, que no da espera, pero sí decae todos los días.

\section{Referencias}

Agamben, Giorgio (1998). Homo Sacer: Sovereign Power and Bare Life. Trans. Daniel Heller-Roazen. Palo Alto: Stanford up, 3-18.

Asad, Talal (2000). What do human rights do? An anthropological enquiry. Theory \& Event, 4(4), xx-xx

Auyero, Javier y Swistun, Debora (2007). Confused because exposed. Towards an ethnography of environmental suffering. Ethnography, 8(2), 123-144.

Berlant, Lauren (2007). Slow death (sovereignty, obesity, lateral agency). Critical Inquiry, 33(4), 754-780.

Bijker, Wiebe E.; Bal, Roland y Hendriks, Ruud (2009). The paradox of scientific authority: The role of scientific advice in democracies. Cambridge: MIT Press.

Brown, Phil (1992). Popular epidemiology and toxic waste contamination: lay and professional ways of knowing. Journal of Health and Social Behavior, 267-281.

Cerrejón (2016). Comentarios de Cerrejón al informe de Cinep Minería, Conflictos Agrarios y Ambientales en el Sur de La Guajira. Recuperado de https:// business-humanrights.org/sites/default/files/documents/Respuesta \%20 Cerrej \% C3 \% B3n \% 20junio \% 2028 \% 202016.pdf

Charters, Claire y Stavenhagen, Rodolfo (Eds.). (2009). Making the declaration work: The United Nations declaration on the rights of indigenous peoples. Copenhagen: IWGIA.

Douzinas, Costas (2000). The end of human rights: critical thought at the turn of the century. Oxford: Bloomsbury Publishing.

Edelman, Marc (2014). Linking the Rights of Peasants to the Right to Food in the United Nations. Law, Culture and the Humanities, 10(2), 196-211.

Fassin, Didier (2007). Humanitarianism as a Politics of Life. Public Culture, 19(3), 499. 
Fiske, Amelia (2016). Evidence of Harm: Oil, Health, and the Environment in the Ecuadorian Amazon (Disertación Doctoral). University of North Carolina, Chapel Hill, 2016.

Ferry, Elizabeth Emma (2013). Minerals, collecting, and value across the USMexico border. Bloomington: Indiana University Press.

Foster, John Bellamy (2000). Marx's ecology: Materialism and nature. Nueva York: NYU Press.

Graeber, David (2001). Toward an anthropological theory of value: The false coin of our own dreams. Londres: Springer.

Graeter, Stefanie (2017). To Revive an Abundant Life: Catholic Science and Neoextractivist Politics in Peru's Mantaro Valley. Cultural Anthropology, 32(1), 117-148.

González Núñez, Denise (2014). Peasants’ Right to Land: Addressing the Existing Implementation and Normative Gaps in International Human Rights Law. Human Rights Law Review, 14(4), 589-609.

Jelin, Elizabeth (2003). State repression and the labors of memory. Minneapolis: University of Minnesota Press.

Keck, Margareth. E. y Sikkink, Katrhyn (2014). Activists beyond borders: Advocacy networks in international politics. Nueva York: Cornell University Press.

Latour, Bruno (2005). From Realpolitik to Dingpolitik or How to Make Things Public. En: B. Latour y P. Weibel, Making Things Public. Atmospheres of Democracy. (pp. 14-43).

Latour, Bruno y Woolgar, Steve (2013). Laboratory life: The construction of scientific facts. Princeton: Princeton University Press.

Li, Fabiana (2015). Unearthing conflict: corporate mining, activism, and expertise in Peru. Durham: Duke University Press.

Merry, Sally Engle (2006). Transnational human rights and local activism: Mapping the middle. American Anthropologist, 108(1), 38-51.

Mignolo, Walter D. (2009). Who speaks for the "human" in human rights. Hispanic Issues On Line, 5(1), 7-24. 
Moore, Jason W. (2011). Transcending the metabolic rift: a theory of crises in the capitalist world-ecology. The Journal of Peasant Studies, 38(1), 1-46.

Moyn, Samuel (2010). The Last Utopia. Cambridge: Harvard University Press.

Nixon, Rob (2011). Slow Violence and the Environmentalism of the Poor. Cambridge: Harvard University Press.

Sassen, Saskia (2006). Territory, authority, rights: From medieval to global assemblages (Vol. 4). Princeton: Princeton University Press.

Smith, Neil (2010). Uneven development: Nature, capital, and the production of space. Athens: University of Georgia Press.

Theidon, Kimberly (2012). Intimate enemies: violence and reconciliation in Peru. Filadelfia: University of Pennsylvania Press.

Ticktin, Miriam I. (2011). Casualties of care: Immigration and the politics of humanitarianism in France. Los Angeles: University of California Press.

Verdery, Katherine (2003). The Vanishing Hectare: Property and Value in Postsocialist Transylvania. Nueva York: Cornell University Press. 